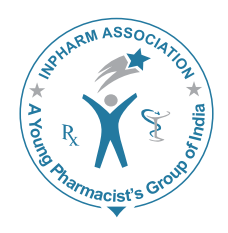

\title{
Formulation Development and Evaluation of Alginate Microspheres of Ibuprofen
}

\author{
Nagpal M, Maheshwari DK' ${ }^{1}$, Rakha $\mathrm{P}^{2}$, Dureja $\mathrm{H}^{3}$, Goyal ${ }^{4}$, Dhingra ${ }^{5}$ \\ Department of Pharmaceutics, College of Pharmacy, Chitkara University, Patiala, Punjab, ${ }^{1}$ Pharmaceutics, \\ and ${ }^{2}$ Pharmacology, Rajendra Institute of Technology and Sciences, Sirsa, Haryana, ${ }^{3}$ Pharmaceutics, \\ M. D. University, Rohtak, ${ }^{4}$ Pharmaceutical Chemistry, Malwa College of Pharmacy, Bhatinda, Punjab, and \\ ${ }^{5}$ Pharmaceutics, NCRD Sterling Institute of Pharmacy, Nerul, Navi Mumbai, Maharashtra, India
}

Address for correspondence: Prof. Manju Nagpal; E-mail: nagpalmanju@ymail.com

\begin{abstract}
The present study was designed to investigate the effects of different variables on the release profile of ibuprofen microspheres formulated using modified emulsification method. Eight batches of microspheres (F1-F8) were prepared by applying $2^{3}$ factorial design. The amount of sodium alginate, amount of calcium chloride, and amount of magnesium stearate were selected as formulation variables. All the batches were evaluated in terms of percentage yield, percentage encapsulation efficiency and in vitro release characteristics. The batch F7 was found to be optimum batch and was further characterized via scanning electron microscopy (SEM) and particle size analysis. Multiple linear regression was applied to confirm significant effect of each variable on release characteristics. The model developed in the present study can be effectively utilized to achieve the formulation with desired release characteristics.
\end{abstract}

Keywords: Factorialdesign, microsphere, multipleregression, particlesizeanalysis, scanning electron microscopy

\section{INTRODUCTION}

Microencapsulation is well known method to delay and modify drug release characteristics. For oral use, it has been employed to sustain the drug release and to reduce or eliminate gastrointestinal tract irritation. ${ }^{[1]}$ It is a process of enclosing micron size particles of solid or liquid or gases in

\begin{tabular}{|l|l|}
\hline \multicolumn{2}{|c|}{ Access this article online } \\
\hline Quick Response Code: & \\
\hline & Website: \\
\hline & www.jyoungpharm.in \\
& DOI: \\
\hline
\end{tabular}

an inert shell resulting in the formation of microparticles or microcapsules or microspheres. ${ }^{[2]}$ As multiparticulate drug delivery lead to wide and uniform distribution throughout GIT, a localized high concentration at a specific point may be avoided. In addition, multiparticulate delivery systems spread out more uniformly in the gastrointestinal tract. This results in more reproducible drug absorption and reduces local irritation when compared to single unit dosage form such as non disintegrating polymeric matrix tablets. ${ }^{[3]}$ Ibuprofen is a potent nonsteroidal antiinflammatory drug with a plasma halflife of 1.8-2 h. It is used for relief of symptoms from arthritis, primary dysmenorrhea, fever and as analgesic especially where there is an inflammatory component. Ibuprofen appears to have the lowest incidence of gastrointestinal adverse drug reactions (ADRs) of all the non-selective NSAIDs. However, 
this only holds true at lower doses of ibuprofen, so over-thecounter preparations of ibuprofen are generally labeled to advise a maximum daily dose of $1200 \mathrm{mg}$. Common adverse effects include nausea, dyspepsia, gastrointestinal bleeding, raised liver enzymes, diarrhea, dizziness, unexplained rash, salt and fluid retention, and hypertension. ${ }^{[4]}$ Sodium alginate, a natural polysaccharide which is a mixture of polyuronic acids composed of residues of D-mannuronic acid and L-guluronic acid. ${ }^{[5]}$ Alginates have the ability to form gels by reaction with divalent cations $\left(\mathrm{Ca}^{2+}\right)$. The gelation and crosslinking of the polymers are mainly achieved by exchange of sodium ions from the guluronic acids with divalent cations, and the stacking of these guluronic groups to form the characteristic egg-box structure. The divalent cations bind to the $\alpha$-L-guluronic acid blocks in the highly cooperative manner and the size of the cooperative unit is more than 20 monomers. Each alginate chain dimerizes to form junctions with many other chains and as the result gel network are formed. ${ }^{[6]}$ Alginate shrinks at the low $\mathrm{pH}$ and the encapsulated drugs are not released. In gastric fluid, the hydrated sodium alginate is converted into porous, insoluble so-called alginic acid skin. Once passed into higher $\mathrm{pH}$ of the intestinal tract, the alginic skin is converted to soluble viscous layer. This $\mathrm{pH}$ dependent behavior of alginate can be exploited to customize release profiles. ${ }^{[6,7]}$ To design a new formulation in the field of pharmaceutical dosage forms, it is very important to identify the parameters and variables in the method of preparation that may affect the properties of the new dosage form. Statistical design can be used for analyzing the influence of different factors on the properties of the system being studied. ${ }^{[8]}$

The present study was carried out to explore the potential of statistical design in optimizing the variables affecting the preparation of microspheres and release profile of ibuprofen from sodium alginate cross linked microspheres were also studied.

\section{MATERIALS AND METHODS}

Ibuprofen (Franklin Pharmaceuticals, Ludhiana, India), Sodium alginate, Calcium Chloride, Magnesium Stearate (Leochem Pvt. Ltd. India), Light Paraffin Wax, Hexane, Isopropyl Alcohol, (Rankem Ltd. India). All the chemicals were of analytical grade.

\section{Methods}

\section{Preparation of microspheres by modified emulsification method}

The microspheres were prepared by using modified emulsification method as reported by Rahman et al..$^{\left[{ }^{9]}\right.}$ The drug was dispersed in aqueous solution of sodium alginate (2.5-7.5 g) with magnesium stearate $(0-2 \mathrm{~g})$. The solution was emulsified in liquid paraffin containing span 80 using a mechanical stirrer at $1700 \mathrm{rpm}$ for $1 \mathrm{~h}$. After this, calcium chloride (2.5-5.0 g) solution (in isopropyl alcohol) was added to the emulsion at the rate of $2 \mathrm{ml} / \mathrm{min}$. The emulsion was stirred for 10 more min. Microspheres formed in organic phase were removed by filtration and washed with hexane to remove liquid paraffin. Microspheres were then vacuum dried for $48 \mathrm{~h}$. The composition of different batches is shown in Table 1 .

\section{Evaluation of microspheres}

Percentage yield: The percentage yield of microspheres was determined from the ratio of solidified total microspheres to the solid material used in the inner phase multiplied by $100 .{ }^{[10]}$

Percentage encapsulation efficiency: $20 \mathrm{mg}$ microsphere sample was dissolved in $20 \mathrm{ml}$ of phosphate buffer $\mathrm{pH}$ 7.4 and kept for overnight. The solution was filtered to remove exhausted microspheres. The UV absorbance of the solution was measured using a UV spectrophotometer at $269 \mathrm{~nm}$. Percentage encapsulation efficiency was determined in duplicate for all batches using equation given below. ${ }^{[1]}$

Encapsulation efficiency $=($ actual amount of Ibuprofen in sample/theoretical amount of Ibuprofen $) \times 100$.

In vitro dissolution studies: In vitro dissolution studies of alginate microspheres was performed using USP II dissolution apparatus at $50 \mathrm{rpm}$ at $37 \pm 0.5^{\circ} \mathrm{C}$ in the $900 \mathrm{ml}$ of gastric fluid ( $\mathrm{pH}$ 1.4) for $2 \mathrm{~h}$ followed by $900 \mathrm{ml}$ of intestinal fluid $(\mathrm{pH} 7.4)$ for $10 \mathrm{~h}$. The sample $(10 \mathrm{ml})$ withdrawn at specific intervals was replenished with equal volume of fresh dissolution media and filtered. The concentration of drug release from alginate microspheres as function of time was determined by using a UV spectrophotometer at $269 \mathrm{~nm}$.

Scanning electron microscopy: Sample of microspheres were mounted onto the stubs using double-sided adhesive tape and then coated with gold palladium alloy (150-200 $\AA$ ) using fine coat ion sputter (Joel, JPC-1100). The samples

\begin{tabular}{|c|c|c|c|c|}
\hline Batch code & $\begin{array}{l}\text { Amount of } \\
\text { sodium } \\
\text { alginate } \\
\text { (g) } X_{1}\end{array}$ & $\begin{array}{c}\text { Amount } \\
\text { of } \\
\mathrm{CaCl}_{2}(\mathrm{~g}) \\
\mathrm{X}_{2} \\
\end{array}$ & $\begin{array}{c}\text { Amount of } \\
\text { magnesium } \\
\text { stearate } \\
\text { (g) } X_{3}\end{array}$ & $\%$ CDR \\
\hline F1 & $-1(2.5)$ & $-1(2.5)$ & $-1(0)$ & 90.9 \\
\hline F2 & $-1(2.5)$ & $-1(2.5)$ & $1(2)$ & 88 \\
\hline F3 & $-1(2.5)$ & $1(5.0)$ & $-1(0)$ & 85 \\
\hline $\mathrm{F} 4$ & $-1(2.5)$ & $1(5.0)$ & $1(2)$ & 84 \\
\hline F5 & $1(7.5)$ & $-1(2.5)$ & $-1(0)$ & 81.1 \\
\hline F6 & $1(7.5)$ & $-1(2.5)$ & $1(2)$ & 82.2 \\
\hline F7 & $1(7.5)$ & $1(5.0)$ & $-1(0)$ & 72.24 \\
\hline F8 & $1(7.5)$ & $1(5.0)$ & $1(2)$ & 75.5 \\
\hline $\mathrm{X}$-coefficient & -4.6075 & -3.1825 & 0.0575 & $\begin{array}{c}82.3675 \\
\text { (constant) }\end{array}$ \\
\hline
\end{tabular}


were subsequently analyzed under the scanning electron microscope for external morphology.

Particle size: Particle size of microspheres was analyzed using laser light diffraction technique (Malvern Instrument, Mastersizer 2000). The homogenous aqueous dispersion of microspheres was used for determining the particle size.

\section{Statistical design}

Most formulation studies involve the variation of one factor at a time, keeping other factors constant. Such an empirical method is acceptable only when factors are independent of one another. The factorial designs allow all factors to be varied simultaneously, thus enabling evaluation of effect of each variable at each level and showing interrelationship among them. A $2^{3}$ factorial design was used sequentially to study the effect of independent formulation variables (amount of sodium alginate, amount of calcium chloride and amount of magnesium stearate) on the release profile of ibuprofen from sodium alginate microspheres.

\section{RESULT AND DISCUSSION}

The microspheres were prepared by modified emulsification method. Preliminary batches (A1-A4) were prepared to obtain discrete microspheres. The different variables i.e. amount of sodium alginate, calcium chloride and magnesium stearate were selected. The above batches were evaluated in terms of in vitro release studies and encapsulation efficiency. It was found that presence of magnesium stearate leads to good encapsulation efficiency. The increasing concentration of $\mathrm{CaCl}_{2}$ (up to $7.5 \mathrm{~g}$ ) led to increased viscosity thereby affecting crosslinking process during microencapsulation. On the basis of these studies, further eight formulation batches (F1-F8) were prepared by applying a $2^{3}$ factorial design by considering three factors i.e. the amount of polymer, sodium alginate $(2.5 \mathrm{~g}$ and $7.5 \mathrm{~g})$, calcium chloride $(2.5 \mathrm{~g}$ and $5.0 \mathrm{~g}$ ) and dispersing agent, magnesium stearate $(0 \mathrm{~g}$ and $2 \mathrm{~g})$ with two levels.

The $\%$ yield of different batches (F1-F8) was found to be 66.6\%-96.6\% [Figure 1].

Increased encapsulation efficiency was observed in formulations at high level of magnesium stearate (F2, F4, F6, and F8). It may be due to the presence of magnesium stearate that was partly lost from inner phase. The high levels of sodium alginate lead to increased encapsulation efficiency whereas percentage encapsulation efficiency decreases with the increase in concentration of calcium chloride. For microspheres cross linked with low level of calcium chloride showed higher drug encapsulation efficiency in comparison to high levels of calcium chloride This may be due to the instant gelling of sodium alginate on addition of calcium chloride and squeezing out of the aqueous phase from gel lattice [Figure 1].

The in vitro release profile from different batches is depicted in Figure 2. The batches F7 and F8 showed sustained release as compared to other batches. This may be due to increase in the density of the polymer matrix and the diffusional path length that the drug has to traverse. It may be due to high concentration of sodium alginate (F5-F8).

Scanning electron micrograph of batch F7 [Figure 3] showed that alginate microspheres are discrete and spherical in shape with a rough outer surface. The particle size of microspheres was found to be $6.8983 \mu \mathrm{m}$.

\section{Data analysis}

To determine the magnitude of contribution of different factors toward \%CDR, multiple linear regression analysis was performed [Table 2]. It showed that \% cumulative

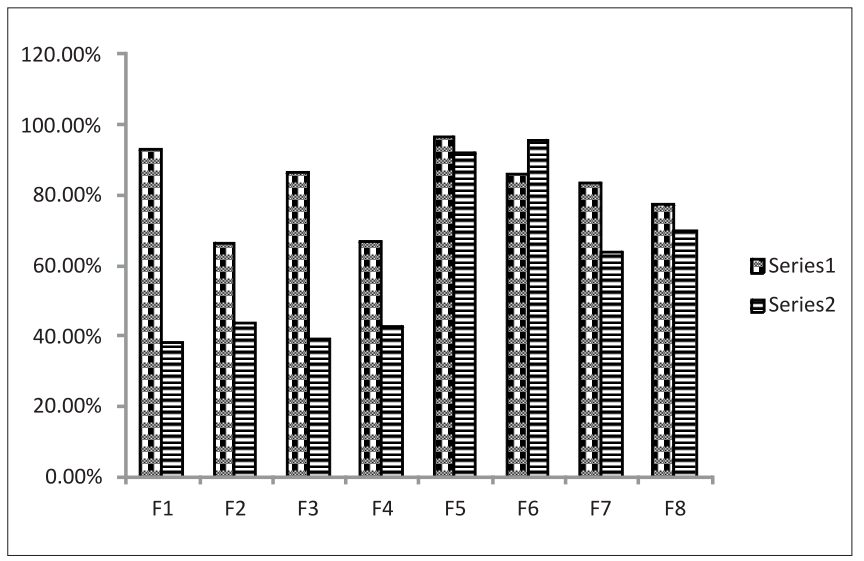

Figure 1: Percentage yield (series 1) and percent encapsulation efficiency (series 2)

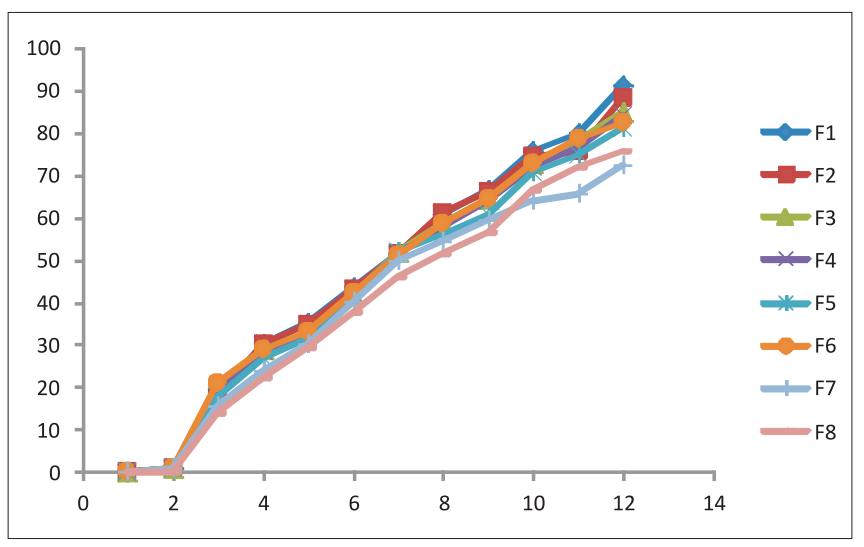

Figure 2: In vitro dissolution profile of formulation batches (F1-F8) 
Table 2: ANOVA of regression (cumulative percent of drug release)

\begin{tabular}{lccccc}
\hline & df & SS & MS & F & Significance $\boldsymbol{F}$ \\
\hline Regression & 3 & 250.8854 & 83.62845 & 22.90908 & 0.005567 \\
Residual & 4 & 14.6018 & 3.65045 & & \\
Total & 7 & 265.4872 & & & \\
\hline
\end{tabular}

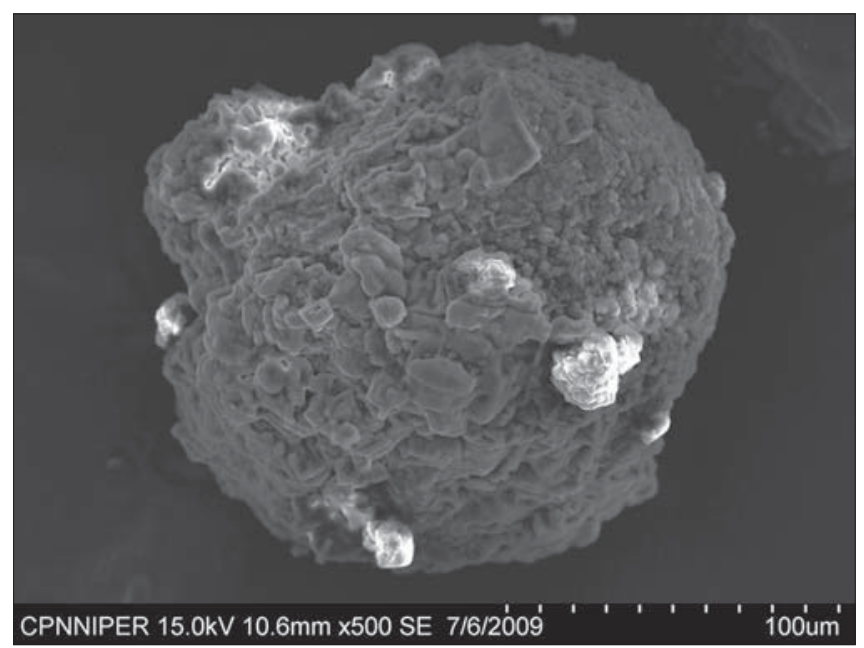

Figure 3: Scanning electron micrograph of batch F7 microspheres at $\times 500$

drug release decreases with increase in the both the concentration of sodium alginate and concentration of $\mathrm{CaCl}_{2}$. The effect of magnesium stearate on the $\% \mathrm{CDR}$ was found to be negligible. The model, developed from multiple linear regression to estimate \%cumulative drug release $(\mathrm{Y})$ can be represented mathematically as:

$\% \operatorname{CDR}(\mathrm{Y})=82.37-4.607 * \mathrm{X}_{1}-3.182 * \mathrm{X}_{2}+0.057 * \mathrm{X}_{3}$

Where $\mathrm{Y}=\%$ cumulative drug release

$\mathrm{X}_{1}=$ Amount of Sodium alginate

$\mathrm{X}_{2}=$ Amount of $\mathrm{CaCl}_{2}$

$\mathrm{X}_{3}=$ Amount of magnesium stearate.

Analysis of variance (ANOVA) was applied to study the fitting and significance of mathematical model to estimate $\%$ CDR. The obtained $F$-value shows regression to be significant.

\section{CONCLUSION}

Microspheres are one of the microparticulate systems and are prepared to obtain prolonged or controlled drug delivery, to improve bioavailability or stability and to target drug to specific sites. Microspheres can also offer advantages like limiting fluctuation within therapeutic range, reducing side effects, decreasing dosing frequency and improving patient compliance. Microspheres of ibuprofen were prepared according to the $2^{3}$ factorial design using modified emulsification method by selecting concentration of sodium alginate, magnesium stearate and calcium chloride as independent variables. Increasing polymer concentration led to more sustained release effect whereas presence of magnesium stearate improves the encapsulation efficiency. Calcium chloride can be increased up to certain limit above which encapsulation was decreased. Moreover, the effect of each variable on release characteristic was found to be significant as confirmed by data analysis. Retrospectively, the mathematical model developed in the present study can be used to design microspheres of desired release characteristic.

\section{ACKNOWLEDGMENT}

The authors are thankful to Franklin Pharmaceuticals, Ludhiana, India for providing the gift sample of Ibuprofen and NIPER, Mohali for SEM facilities and particle size analysis.

\section{REFERENCES}

1. Allen LV, Popovich NG, Ansel HC editors. Ansel's Pharmaceutical Dosage Forms and Drug Delivery Systems. $9^{\text {th }}$ EDITION, New York: Lippincott Williams and Wilkins; 2005.

2. Ghosh SK, editors. Functional Coatings and Microencapsulation: A general perspective. 2006, Weinheim: Wiley-VCH GmBH and Co. KGaA; 2006.

3. Sam MT, Gayathri DS, Prasanth V, Vinod B. NSAIDs as microspheres. Int J Pharmacology 2008;6:1

4. Devrim B, Canefe K. Preparation and evaluation of modified release ibuprofen microspheres with acrylic polymers (eudragit) by quasi emulsion solvent diffusion method: Effect of variables. Acta Poloniae Pharm Drug Res 2006;63:521-34.

5. Rastogi R, Sultana Y, Aqil M, Ali A, Kumar S, Chuttani K, Mishra AK. Alginate microspheres of Isoniazoid for oral sustained drug delivery. Int. J Pharm 2007;334:71-7.

6. George M, Abraham TE. Polyionic hydrocolloids for the intestinal delivery of protein drugs alginate and chitosan-a-review. J Controlled Release 2006;114:1-14.

7. Lee BJ, Cui JH, Kim TW, Heo MY, Kim CK. Biphasic release characteristics of dual drug loaded alginate beads. Arch Pharm Res 1998;21:645-50.

8. Chawla V, Tiwari AK, Gupta S. Characterization of polyvinyl alcohol microspheres of diclofenace sodium application of statistical design. Drug Dev Ind Pharm 2000;26:675-80.

9. Rahman Z, Kohli K, Khar RK, Ali M, Charoo NA, Shamsher AA. Characterization of 5-fluorouracil microspheres for colonic delivery. AAPS PharmSciTech 2006; 7:E47.

10. Horoz BB, Kliçarslan M, Yüksel N, Baykara T. Influence of aluminum tristearate and sucrose stearate as the dispersing agents on physical properties and release characteristics of eudragit RS microspheres. AAPS PharmSciTech 2006; 7:E16.

11. Thompson CJ, Hansford D, Higgins S, Rostron C, Hutcheon GA, Munday DL. Evaluation of ibuprofen-loaded microspheres prepared from novel copolyesters. Int J Pharm 2007;329:53-61.

How to cite this article: Nagpal M, Maheshwari DK, Rakha P, Dureja $\mathrm{H}$, Goyal S, Dhingra G. Formulation development and evaluation of alginate microspheres of ibuprofen. J Young Pharmacists 2012;4:13-6.

Source of Support: Nil, Conflict of Interest: None declared. 